\title{
O QUE É E QUALÉ O LUGAR DO TRANSCENDENTE NA FILOSOFIA? UMA NOTA A PARTIR DE G. W. F. HEGEL'
}

Humberto Schubert Coelho

Resumo: O termo transcendência tem conotações fortemente dualistas na concepção do senso comum, na qual ele é oposto de maneira dualística à imanência. Consequentemente, tanto concepções populares quanto especializadas do transcendente atribuem-no ao celestial, supramundano ou espiritual, e, portanto, matéria do discurso poético ou religioso. Ao passo que este entendimento usual do termo justificou (historicamente) e é de fato incompatível com as tentativas de domesticação ou eliminação da metafísica da meditação filosófica contemporânea, outras significações são possíveis. Uma famosa e bem-sucedida visão sobre a transcendência é a hegeliana, segundo a qual a transcendência não apenas é constituída intersubjetivamente como a universalidade das coisas como também dialeticamente codependente do concreto e do imanente.

Palavras-chave: Transcendente; Objetividade; Concretude; G. W. F. Hegel.

Abstract: The term transcendence has a distinct dualistic feature in the broader cultural understanding, in which it is opposed to immanence. As a consequence of this view, both commonsensical and specialized conceptions of the transcendent attribute it to the heavenly, outworldly or spiritual, and hence subject of religious or poetical discourse. While this usual understanding of the term justified and is in fact compatible with the attempts of domesticating or eliminating metaphysics from contemporary philosophical meditation, other understandings do exist. One very successful and influential view about the transcendence is the Hegelian one, according to which transcendence is not only intersubjectively constituted as the universality of things, but also dialectically co-dependent of the concrete and immanent.

Keywords: Transcendent; Objectivity; Concreteness; G. W. F. Hegel.

\footnotetext{
${ }^{1}$ Pesquisa parcialmente financiada pela Clínica Jorge Jaber e pelo Instituto Homero Pinto Vallada. Também agradeço à UFJF por apoiar com bolsas de iniciação científica alunos que se dedicam ao Núcleo de Filosofia Clássica Alemã. Por fim, agradeço a Luíz Filipe da Silva Oliveira por sua cooperação com este e outros trabalhos meus sobre o pensamento de Hegel.
} 


\section{O ambíguo status da transcendência na pesquisa contemporânea}

Ao passo que o conceito de transcendência permanece razoavelmente claro como horizonte normativo e regulativo dos limites da existência e do entendimento humanos, seu lugar na meditação filosófica contemporânea tornou-se matéria de controvérsia ou foi relegado a um esquecimento deliberado. Como consequência da "morte de Deus", evento de origem filosófica e só secundariamente teológico, a metafísica passou a ser questionada em sua vinculação histórica com a teologia ainda que apenas uma teologia filosófica, em alguns casos - a religião ou especificamente a fé cristã. Seguiu-se um inevitável ou, ao menos, previsível processo de purificação da metafísica que, em alguns casos beirou à ameaça de extinção.

Contra muitas projeções, contudo, a transcendência parece resistir às sucessivas tentativas de purificação de resíduos metafísicos dos mais diversos discursos filosóficos, teológicos e até científicos, revelando-se conceito mais polissêmico e pervasivo que o imaginado.

A filosofia começa por ser recursiva e não objetal pelo fato de incluir em si uma larga porção de metafilosofia, ou seja, a busca por sua própria definição. Mesmo autores irracionalistas e antissistemáticos como Novalis enxergaram nesta a "tarefa fundamental da filosofia" (NOVALIS. 1901, II, 593), e autores que se pronunciaram desfavoravelmente a ela, como Karl Popper, tinham ainda uma concepção, às vezes robusta e clara, do que era e de como operava a filosofia.

O romântico diria que "só um homem completo pode produzir a filosofia completa" (NOVALIS. 1901, II, 625), com intuito inconfundivelmente sentimentalista. O filósofo da ciência, no espectro oposto, condena a psicanálise e o marxismo como pseudociências em contraste com as quais melhor identificamos o critério de objetividade das ciências da natureza (POPPER, 2001). Também em suas famosas críticas a G. W. F. Hegel na $A$ sociedade aberta e seus inimigos, o filósofo objetivista havia dirigido impressionantes ataques à ideia de um absolutismo histórico, supostamente presente na obra de Hegel. Apesar de o projeto científico em meados do século XX demandar de Popper que ele tivesse um olho no positivismo e 
outro no pragmatismo, suas críticas pareciam também reforçar a percepção geral de que seu coração estava com um racionalismo crítico de tipo kantiano.

Até que ponto, contudo, projetos negativos ou minimalistas como os de I. Kant, K. Popper ou B. Russel realmente escapam do horizonte de eventos a partir do qual a atração à recursividade filosófica é irresistível? E mesmo que escapassem completamente, de que maneira isso confirmaria a impressão de alguns de que há uma filosofia integralmente consequente, analítica e/ou puramente lógica ou formal? Por fim, essa filosofia "pura" conteria menos referências transcendentes ou à transcendência que as outras e supostamente mais comprometidas expressões filosóficas?

No caso de Kant, há tanto razão para supor que ele "entregou os resultados sem apresentar as premissas" (SCHELLING, AA III, I, Carta a Hegel de 06 de Janeiro de 1795) quanto para supor que ele na verdade manteve suficientemente os horizontes da transcendência como marcos de seu pensamento. Em outras palavras, ele de certo modo não eliminou as pressuposições metafísicas de sua filosofia ao ignorá-las ou deixa-las apenas implícitas, e, ao mesmo tempo, tratou extensamente das ideias transcendentes como regulativas, como postulações necessárias ao sentido da vida moral ou mesmo como não passíveis de constituir conhecimento, embora não cabalmente inválidas ${ }^{2}$.

No caso dos autores do século XX, por outro lado, é válido perguntar se o impasse causado pelo embate de Thomas Kuhn a Popper (LAKATOS; MUSGRAVE, 1970) ou a defecção de Ludwig Wittgenstein em relação ao atomismo de Russel (WITTGENSTEIN, 1958; NYGREN, 1972, 254-262) não evidenciam justamente a natureza não exaustiva ou relativamente não-objetiva do pensamento humano. Naquilo em que foram excepcionalmente bem-sucedidos, contudo, esses mesmos autores reconheceram e enfatizaram numerosas vezes a imprescindibilidade

\footnotetext{
${ }^{2} \mathrm{O}$ segundo grupo muito provavelmente constitui o sentido forte do termo transcendente em sua acepção mais comum, e na Crítica da razão prática (2003) Kant situa as ideias de imortalidade da alma e de Deus como supremo garantidor da ordem moral como ideias que ultrapassam o escopo investigativo da razão, mas que não obstante são pensáveis como horizonte extrapolado a partir do qual o sentido da toda ação humana encontra razoabilidade última.
} 
da metafísica, e que sua busca por rigor deveria significar mais uma insistência em permanecer no terreno da clareza conceitual do que uma proibição intransigente ao diverso.

Enquanto a filosofia (mais uma vez) se reinventa para compreender como um discurso racional - necessariamente metafísico e, por isso, com referenciais transcendentes - é possível diante das críticas antropoligizantes do século XX, as neurociências e alguns ramos da psicologia anexos a estas ajudam a entender como as funções predominantemente semânticas e contextuais do lado direito do cérebro regem as funções lógicas, analíticas e espaciais do lado esquerdo (MCGILCHRIST, 2009), e como a função de neurônios espelho e o fenômeno de atenção compartilhada ajudam a explicar de que maneira pensamentos e percepções são intersubjetivamente constituídos (FRITH, FRITH, 2007).

Não parece existir mais, portanto, um caminho para o realismo ingênuo, como se o mito da correspondência direta ou eficaz entre uma mente "pura" e um objeto discreto com informação e verdade disponíveis em si pudesse ocorrer. Ao invés disso, transformações em correntes filosóficas tão diversas quanto a filosofia analítica e a continental convergiram, até certo ponto, para o reconhecimento do papel da sociabilidade na constituição do pensamento. Paulatinamente, uma maior demanda por integração multidisciplinar entre a filosofia, as ciências sociais quantitativas e as neurociências, consolidaram ao longo das últimas décadas a relevância das redes contextuais e semânticas dadas intersubjetivamente tramadas como cultura.

Visto que ele é foi o inventor ou primeiro apresentador sistemático dessa ideia, deveríamos voltar a Hegel.

\section{O transcendente-imanente de Hegel}

Desgostosos com ou indiferentes à secura de propostas como a de David Hume, o espectro da filosofia alemã na virada do século XIX gravitava da sobriedade do criticismo de Kant à intuição sonhadora do romantismo de Novalis. Entre esses 
extremos uma maior quantidade de propostas tentava conciliar o ímpeto de domesticar o transcendente ao ímpeto de tudo entregar a ele.

Um romântico mais moderado como F. Schleiermacher, que aplicou as ferramentas de Kant à visão de mundo de Espinosa, não apenas libertou a religião de sua ancestral dependência a ideias sobrenaturais em favor de um conceito científico de intuição religiosa universal como também tornou o objeto da intuição religiosa o mesmo da investigação metafísica. O mesmo infinito ou absoluto sobre o qual a metafísica discursa dialeticamente é o fundamento ou Deus que a religião apreende como "sentimento" tácito da consciência finita em face de um universo infinito que a comporta.

Ao nos afastarmos um passo a mais do romantismo radical de Novalis em direção a uma proposta que pretenda nada menos que a exposição científica da verdade, com G. W. F. Hegel, entendemos que tal pretensão só pode residir em conformidade com o ideal de uma ciência pura, isto é, que "contenha o pensamento na medida mesma em que este é a própria coisa, ou a coisa na medida em que é ele mesmo (pensamento)" (HEGEL, 1970, V, 42).

O modo como Hegel escolhe afastar-se do romantismo radical, contudo, não o leva a retornar à posição kantiana. No afã de constituir a filosofia como ciência, J. G. Fichte havia iniciado uma alternativa ao minimalismo transcendental de Kant, sugerindo que a constituição da própria realidade, na medida em que transcendentalmente condicionada, não poderia ser outra que não um sujeito absoluto (FICHTE, 1965, 47; 258-260). Este o caminho que F. W. J. Schelling e Hegel tomariam como destino (logicamente) inevitável da filosofia críticatranscendental, pois conducente à recomposição metafísica entre a subjetividade e a objetividade, o Eu e o mundo, o pensamento e a substância.

Acompanhando e concluindo o percurso do conceito de substância ao longo da tradição metafísica moderna, muito com referência a Espinosa, Hegel definirá a substância como sujeito (HEGEL, 1970, III, 27), na medida em que a verdade tem de dizer respeito ao todo (HEGEL, 1970, III, 23), e uma vez que, desde Platão e 
Aristóteles, toda percepção e todo discurso possíveis sobre o ser e seus modos são inevitável e radicalmente mediados e/ou formatados pela subjetividade.

A referida ciência pura, então, merece ser denominada lógica, e "deve ser concebida, assim, como o sistema da razão pura, enquanto reino do puro pensamento" (HEGEL, 1970, V, 42-43). Não pode, também, falar senão do pensamento concreto em oposição ao nada, que não é e nada pode engendrar ( $E x$ nihilo nihil fit) (HEGEL, 1970, V, 83-84). Só pode, então, falar do ser e do real, do efetivo, ainda que para falar do real, do efetivo e do verdadeiro tenha que explicar o papel da negatividade, da abstração e do próprio nada na constituição dos primeiros.

Ora, o que está aí só pode estar enquanto um ser mediado pelo vir a ser. O ser efetivado (sendo e estando) é o concreto, enquanto um ser não efetivo é por definição irreal e abstrato, puramente mental contraposto ao real. O pensamento, no entanto, é capaz de apreender perfeitamente bem a diferença entre um tal ser abstrato e um concreto e realizado, ou efetivo, pelo que se pode discernir este último pensamento sobre algo que é de um pensamento sobre algo que apenas poderia ser, ou que só no e para o plano do pensamento se apresente. (HEGEL, 1970, VI, 185).

Como toda a exterioridade ou concretude morta é apreendida a partir de um "estranhamento" por parte do sujeito que a compreende, a ideia mais própria ou mais verdadeira é necessária e precisamente a ideia da realidade do sujeito enquanto eminentemente espiritual, isto é, agente ético. Desse modo, a ideia mais perfeita realizável, e que vem a constituir os pontos culminantes da arte, da religião ou da política (HEGEL, 1970, XIII), não pode ser outra se não a ideia do bem ou "agencia divina"; uma agencia que, embora concreta e dada materialmente, expressa o que há de mais racional na natureza: o homem ético (HEGEL, 1970, VI, 544; 548).

Não é possível ignorar que desde escritos de juventude, como Vida de Jesus, passando pela Fenomenologia até as lições de filosofia da religião, Hegel deixa clara a importância da morte de Deus na dinâmica da transcendência (DREHER, 2003; OLIVEIRA, 2019). Afinal, o Deus de Hegel não morre a partir de uma constatação 
Número XXIV - Volume I - junho de 2021 https://periodicos.ufjf.br/index.php/eticaefilosofia

ISSN: $1414-3917$

e-ISSN: 2448-2137

na praça do mercado, como o de Nietzsche. Para Hegel, o Deus puramente transcendente morreu na cruz.

O transcendente não é nem negado nem domesticado como promessa e expectativa para além do ser, aparecendo concretamente na constituição do próprio ser, ainda que, por isso mesmo, não se trate mais de um transcendente diáfano, etéreo e "puro" ou abstrato, e sim de um transcendente concretamente detectado e rastreado como exalação da objetividade da vida. 


\section{REFERÊNCIAS}

DREHER, Luis, H. A questão da morte de Deus. In: FERREIRA, Acylene M. C. (Org.). Fenômeno e Sentido. Salvador: Quarteto, 2003. (73-92)

FICHTE, Johann G. Gesamtausgabe der Bayerischen Akademie der Wissenschaften. Bd. I,2: Werke (1793-1795). Stuttgart: Frommann-holzboog Verlag, 1965.

FRITH, C. D.; FRITH, U. Social Cognition in Humans. Current Biology 17, 16, 2007. (pg. 724-732)

HEGEL, G.W.F. Hegel: Werke in 20 Bänden. Suhrkamp Verlag, 1970.

KANT, Immanuel. Kritik der praktischen Vernunft. Hamburg: Felix Meiner Verlag, 2003.

LAKATOS, Imre; MUSGRAVE, Alan. Criticism and the Growth of Knowledge. Cambridge: Cambridge University Press, 1970.

McGILCHRIST, Iain. The Master and his Emissary: The Divided Brain and the Making of the Western World. New Haven: Yale University, 2009.

NOVALIS. Novalis Schriften. Bd. II. Berlin: Georg Reimer, 1901.

NYGREN, Anders. Meaning and Method. Prolegomena to a Scientific Philosophy of Religion and a Scientific Theology. Eugene: Wipf \& Stock, 1976.

OLIVEIRA, Luiz Filipe da S. O ensaio Fé e Saber como ponto de inflexão: função especulativa e papel histórico da questão hegeliana da morte de Deus. In: ALVES, Eduardo; GABOARDY, Gregory; COSTA, Claiton S.; FRAGA, David (Org.). XIX Semana acadêmica do PPG em Filosofia da PUCRS. Porto Alegre: Editora Fundação Fênix, 2019.

POPPER, Karl. Conjecturas e Refutações. Lisboa: Edições 70, 2001.

SCHELLING, F. W. J. Friedrich Wilhelm Joseph Schelling: Historisch-kritische Ausgabe. Stuttgart: Frooman-Holzboog, 1976.

WITTGENSTEIN, Ludwig. Philosophical Investigations. New York: MacMillan, 1958. 